\title{
ADVERSE EFFECTS OF HYPEROXEMIA DURING CARDIOPULMONARY BYPASS
}

P.-O. Joachimsson, $\mathrm{MD}, \mathrm{PhD}^{\mathrm{d}}$

F. Sjöberg, $\mathrm{MD}, \mathrm{PhD}^{\mathbf{c}}$

M. Forsman, $\mathrm{CCP}^{\mathrm{b}}$

M. Johansson, $\mathrm{MD}^{\mathrm{a}}$

H. Casimir Ahn, MD, $\mathrm{PhD}^{\mathrm{b}}$

H. Rutberg, $\mathrm{MD}, \mathrm{PhD}^{\mathrm{a}}$
Objective: Aiming at elucidating the effects on capillary blood flow and tissue oxygenation of hyperoxemia during cardiopulmonary bypass, we studied skeletal muscle surface oxygen tensions in 10 patients undergoing elective cardiac operations. Methods: In a prospective investigation each patient was exposed to normoxemia (arterial oxygen tension 75 to $115 \mathrm{~mm} \mathrm{Hg}$ ) and hyperoxemia (arterial oxygen tension > $185 \mathrm{~mm} \mathrm{Hg}$, inspired oxygen fraction $=1.00$ ) during normal anesthetized conditions before and after cardiopulmonary bypass, as well as during normothermic and hypothermic continuous-flow bypass. In each state hemodynamic variables and arterial and mixed venous blood gas and acid base values were measured. From these data oxygen transport variables were calculated. Tissue oxygenation was studied with the use of a multiple-point polarographic oxygen microelectrode, known to provide measures of oxygen tensions at the capillary level. The oxygen distribution profile of such a sample is also indicative of capillary blood flow distribution changes. Results: In all patients and at each occasion of the investigation markedly low mean surface oxygen tensions in skeletal muscle were registered. When hyperoxemia was instituted, a significant decrease in these surface oxygen tensions together with an increase in distribution heterogeneity was seen during all stages. Contrary to prebypass, postbypass, and hypothermic bypass, where vascular resistance, oxygen delivery, and oxygen consumption remained similar during hyperoxemia and normoxemia, a significant $(p<0.05)$ increase in vascular resistance together with a decline in oxygen consumption was seen during hyperoxemic normothermic $\left(35^{\circ}\right.$ to $\left.36^{\circ} \mathrm{C}\right)$ cardiopulmonary bypass. Conclusion: These findings show that the microcirculatory response to hyperoxemia, seen under other circumstances, persists during continuous-flow cardiopulmonary bypass, normothermic as well as hypothermic. If these adverse effects on tissue oxygenation by hyperoxemia can be further verified and shown to be valid for other organs than skeletal muscle, we would suggest that hyperoxemia should be avoided, especially during normothermic cardiopulmonary bypass. (J Thorac Cardiovasc Surg 1996;112:812-9)
From the Linköping Heart Center, Department of Cardiothoracic Anesthesiology and Intensive Care ${ }^{\mathrm{a}}$ and the Department of Cardiothoracic Surgery'; the Burns Unit, the Departments of Plastic Surgery and Anesthesiology and Intensive Care; University of Linköping, Linköping, Sweden; and the Department of Anesthesiology and Intensive Care, ${ }^{\mathrm{d}}$ University of Uppsala, Uppsala, Sweden.

Supported by grants from the County Council of Östergötland and the AGA medical research fund.

Received for publication June 30, 1995; revisions requested Oct. 12, 1995; revisions received Jan. 12, 1996; accepted for publication March 19, 1996.

Address for reprints: $\mathrm{H}$. Rutberg, $\mathrm{MD}, \mathrm{PhD}$, Linköping Heart Center, Department of Cardiothoracic Anesthesiology and Intensive Care, University Hospital, S-581 85 Linköping, Sweden.

Copyright 191996 by Mosby-Year Book, Inc

$0022-5223 / 96 \$ 5.00+0 \quad \mathbf{1 2 / 1 / 7 3 5 2 8}$
Deripheral tissue perfusion is disturbed and reduced during hypothermic cardiopulmonary bypass (CPB) with both a reduced flow and a continuous flow pattern., 2 This disturbance has also been demonstrated by a lower average oxygen tension in skeletal muscle. ${ }^{3}$ Under such circumstances it may be tempting to assume that a supernormal arterial oxygen tension $\left(\mathrm{PaO}_{2}\right)$ would provide improved oxygen delivery to peripheral tissue and an increased margin of safety, and often the $\mathrm{PaO}_{2}$ is kept above normal values. On the contrary, however, excessively high $\mathrm{PaO}_{2}$ values may be harmful. Adverse influence of hyperoxemia on red blood cells, perioperative complications, and morbidity during CPB has been reported. ${ }^{4}$ Hyperoxemia also disturbs and reduces tissue oxygenation in healthy subjects under normal resting conditions, as well as in mechanically 
ventilated critically ill patients. This is seen as an increase in the range of tissue oxygen tensions of different adjacent capillary regions, where some extremely low values are observed. ${ }^{5,6}$ The change in oxygen tension distributions seen during hyperoxemia has been found to be due to changes in capillary flow, possibly mediated by serotonin. ${ }^{7}$ It is not known if this response to hyperoxemia is retained during hypothermic CPB. If this is the case, tissue perfusion would be further impaired and possibly inadequate.

Multiple-point microelectrodes for measurement of muscle surface oxygen tensions $\left(\mathrm{PmO}_{2}\right)$ are available and can be sterilized and mounted aseptically for use in the operating field. ${ }^{6,8}$ In this study such an electrode was used to monitor peroneal $\mathrm{PmO}_{2}$ values during cardiac operations.

The aim of the study was to observe the influence of arterial normoxemia and hyperoxemia, respectively, on peripheral muscle oxygenation before, during, and after hypothermic continuous-flow CPB.

\section{Patients and methods}

Patients. Ten adult patients, nine men and one woman, undergoing $\mathrm{CPB}$ for elective cardiac operations were studied during the operation. The patients were selected after giving their informed consent. The study was approved by the Ethics Committee of the University Hospital of Linköping. The surgical procedures were aortic valve replacement in one case, closure with direct suture of an atrial septal defect and coronary artery bypass grafting (CABG) in one case, and $\mathrm{CABG}$ in the other eight cases. Patients undergoing CABG all had threevessel disease. All patients had good or only moderately impaired left ventricular function.

Anesthesia. The patients were premedicated with $1 \mathrm{mg}$ of flunitrazepam on the evening before the operation and oxycodone and scopolamine, 7.5 to $10 \mathrm{mg}$ and 0.3 to 0.4 $\mathrm{mg}$, respectively, 1 to 2 hours before induction of anesthesia. Patients receiving $\beta$-blocking medication (seven of eight patients undergoing $\mathrm{CABG}$ ) were given their ordinary morning dose at the time of premedication. Anesthesia was induced with fentanyl, thiopental, and pancuronium and was maintained with isoflurane $(0.5 \%$ to $0.75 \%$ ) and intermittent doses of fentanyl. The total dose (mean \pm standard deviation) during the operation was 1.4 $\pm 0.5 \mathrm{mg} / \mathrm{kg}$ for thiopental, $25 \pm 7 \mu \mathrm{g} / \mathrm{kg}$ for fentanyl, and $0.10 \pm 0.01 \mathrm{mg} / \mathrm{kg}$ for pancuronium. After intubation, the patients' lungs were mechanically ventilated with an oxygen-in-air mixture, with the inspired oxygen fraction being varied to achieve the desired $\mathrm{PaO}_{2}$. Ventilation was adjusted to provide arterial carbon dioxide tensions within the normal range of 30 to $40 \mathrm{~mm} \mathrm{Hg}$, as well as normal arterial $\mathrm{pH}$ values.

CPB. In all patients the distal portion of the ascending aorta was used as the site for aortic cannulation. Femoral vessels were not manipulated in any way in any patient.
During CPB a standard roller pump heart-lung machine and heating/cooling device (Stöckert CAPS and Stöckert Heater-Cooler, Stöckert Instrumente, Munich, Germany) were used. The membrane oxygenator (Sorin Monolyth, Sorin Biomedica SPA, Saluggia, Italy) and the tubing were primed with 1.5 to $1.7 \mathrm{~L}$ of Ringer's acetate solution and $100 \mathrm{ml}$ mannitol $150 \mathrm{mg} / \mathrm{ml}$. During CPB hemoglobin values of 75 to $90 \mathrm{gm} / \mathrm{L}$ were intended. The $\mathrm{CPB}$ was conducted in a continuous-flow mode. At normothermia the pump flow was $2.2 \mathrm{~L} / \mathrm{min}$ per square meter. During aortic occlusion moderate hypothermia of $28^{\circ} \mathrm{C}$, guided by nasopharyngeal temperature, was induced. After that temperature was reached, a flow of 1.8 to $2.0 \mathrm{~L} / \mathrm{min}$ per square meter was used until rewarming. The gas flow from the oxygenator was adjusted to maintain alpha-stat regulation of acid-base status during hypothermia. Acid-base status, blood gases, and oxygen saturations were checked with intermittent samples analyzed by automated analyzers (ABL 4 and OSM 3, Radiometer A/S, Copenhagen, Denmark). Arterial oxygenation before, during, and after $\mathrm{CPB}$ was altered according to the study protocol. An on-line continuous blood gas monitor (CDI System 400, $3 \mathrm{M}$ Health Care, Tustin, Calif.) with the sensor incorporated in the circuitry was used to facilitate and improve adjustments needed to achieve the intended $\mathrm{PaO}_{2}$ levels during CPB.

Monitoring. Two peripheral venous lines and one arterial cannula in the left radial artery were inserted before induction of anesthesia. After intubation a triple-lumen central venous catheter and a balloon-tipped flow-directed thermodilution fiberoptic pulmonary artery catheter (P7110 Opticath catheter connected to an Oximetrix 3 instrument, Abbott Critical Care systems, Mountain View, Calif.) were inserted percutaneously via the right internal jugular vein. Rectal and nasopharyngeal standard temperature probes were placed. Arterial, pulmonary artery, and central venous pressures were measured with standard transducers. The pressure values, temperatures, intermittent cardiac output measurements, and derived variables were monitored and recorded on the monitoring equipment in the operating room (Hewlett-Packard Merlin System, Hewlett-Packard, North Hollywood, Calif.).

Study protocol. Measurements, including blood gas analyses, hemodynamic variables, and $\mathrm{Pmo}_{2}$ values, were recorded during normoxemia and hyperoxemia on four occasions. On each occasion a stabilization period of 10 to 15 minutes was allowed after switching from normal to high or high to normal $\mathrm{PaO}_{2}$. The first set of measurements, M1, was performed during stable anesthesia after sternotomy and after an initial stabilization period after preparation and mounting of the $\mathrm{Pmo}_{2}$ electrode. Then measurements were first obtained during normoxemia $\left(\mathrm{PaO}_{2}\right.$ in the range of 75 to $\left.115 \mathrm{~mm} \mathrm{Hg}\right), \mathrm{M} 1 \mathrm{~N}$. After that the inspired oxygen fraction was increased to produce hyperoxemia $\left(\mathrm{PaO}_{2}>185 \mathrm{~mm} \mathrm{Hg}\right)$. After the equilibration interval the next measurements of this phase, $\mathrm{M} 1 \mathrm{H}$, were performed. Hyperoxemia was then maintained until stable hypothermic CPB $\left(28^{\circ} \mathrm{C}\right.$ nasopharyngeal temperature) had been established, when the next set of measurements were done, $\mathrm{M} 2 \mathrm{H}$. Then the oxygen supply to the oxygenator was decreased to achieve normoxemia and, after a stabilization period, measurements M2N were 


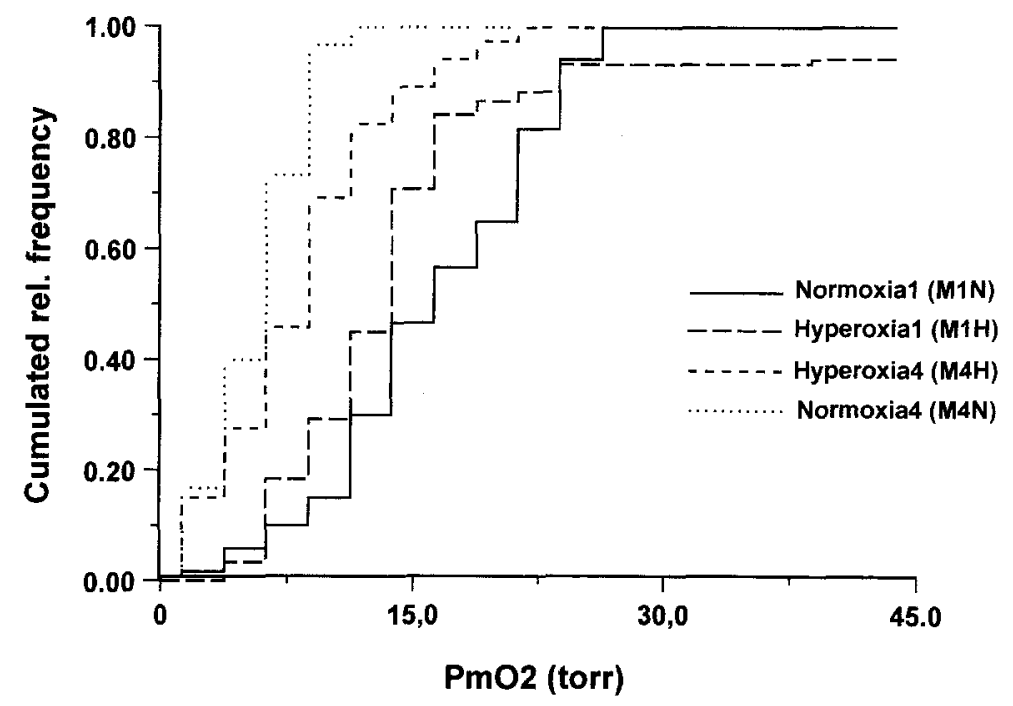

Fig. 1. $\mathrm{PmO}_{2}$ for one patient (No. 6) during normoxemic and hyperoxemic conditions before $\mathrm{CPB}$ (Normoxia 1, M1N, and Hyperoxia 1, M1H), and after CPB (Hyperoxia 4, M4H, and Normoxia, M4N). Values are presented as cumulated relative frequencies on the $y$-axis, with the 0.50 value corresponding to the median. Each of the four histograms is constructed from 120 separate $\mathrm{PmO}_{2}$ values.

Table I. $\mathrm{PaO}_{2}$, temperature, and hemodynamic data at measurement occasions

\begin{tabular}{|c|c|c|c|c|c|c|c|c|}
\hline & \multicolumn{2}{|c|}{ Pre-CPB } & \multicolumn{2}{|c|}{ Cold $C P B$} & \multicolumn{2}{|c|}{ Warm $C P B$} & \multicolumn{2}{|c|}{ Post-CPB } \\
\hline & $M 1 N$ & $M 1 H$ & $M 2 H$ & $M 2 N$ & $M 3 N$ & $M 3 H$ & $M 4 H$ & $M 4 N$ \\
\hline $\mathrm{PaO}_{2}(\mathrm{~mm} \mathrm{Hg})$ & $108 \pm 19$ & $356 \pm 148$ & $284 \pm 65$ & $93 \pm 16$ & $83 \pm 12$ & $281 \pm 48$ & $344 \pm 128$ & $96 \pm 23$ \\
\hline $\operatorname{TNP}\left({ }^{\circ} \mathrm{C}\right)$ & $35.2 \pm 0.2$ & $35.0 \pm 0.2$ & $27.3 \pm 0.3$ & $27.7 \pm 0.3$ & $38.1 \pm 0.4$ & $36.6 \pm 0.2$ & $35.7 \pm 0.5$ & $35.8 \pm 0.5$ \\
\hline $\mathrm{Hb}(\mathrm{gm} / \mathrm{dl})$ & $12.6 \pm 0.5$ & $12.4 \pm 0.5$ & $8.9 \pm 0.4$ & $9.1 \pm 0.4$ & $9.2 \pm 0.4$ & $9.3 \pm 0.4$ & $9.7 \pm 0.4$ & $10.0 \pm 0.5$ \\
\hline $\mathrm{CI}\left(\mathrm{L} / \mathrm{min} / \mathrm{m}^{2}\right)$ & $1.8 \pm 0.1$ & $2.2 \pm 0.1$ & $2.0 \pm 0.1$ & $2.0 \pm 0.4$ & $2.4 \pm 0.1$ & $2.4 \pm 0.1$ & $2.1 \pm 0.1$ & $2.1 \pm 0.1$ \\
\hline $\mathrm{SvO}_{2}(\%)$ & $72.7 \pm 7.8$ & $78.9 \pm 7.9$ & $85.8 \pm 7.7^{*}$ & $80.9 \pm 3.1$ & $67.6 \pm 8.4$ & $79.1 \pm 2.6$ & $72.2 \pm 8.3 \dagger$ & $64.2 \pm 5.3$ \\
\hline
\end{tabular}

All values are presented as mean \pm standard deviation. $M 1 N \ldots M 4 N$, Measurement during normoxemia before CPB, during cold and normothermic CPB, and after $\mathrm{CPB}$, respectively; $M 1 H \ldots M 4 H$, measurement during hyperoxemia at respective stage of surgery; PaO, arterial oxygen tension; TNP, nasopharyngeal temperature; $\mathrm{Hb}$, hemoglobin concentration; $\mathrm{Cl}$, cardiac index; $\mathrm{SvO}_{2}$, oxygen saturation in mixed venous blood. $\mathrm{PaO} \mathrm{O}_{2}, \mathrm{TNP}, \mathrm{Hb}$, and $\mathrm{Cl}$ are manipulated instrumental variables and, hence, are presented without statistical analysis results.

" $p<0.01$, normoxemia versus hyperoxemia.

$\uparrow p<0.05$, normoxemia versus hyperoxemia.

undertaken. After unclamping of the aorta and rewarming to approximately $35^{\circ} \mathrm{C}$ rectal temperature, the third set of measurements were performed, M3N at normoxemia and then $\mathrm{M} 3 \mathrm{H}$ after hyperoxemia was established. The last set of measurements were carried out during stable spontaneous circulation after terminating $\mathrm{CPB}$ and after giving protamine, $\mathrm{M} 4 \mathrm{H}$ during hyperoxemia and finally $\mathrm{M} 4 \mathrm{~N}$ after an equilibration interval with normoxemia.

Hemodynamic measurements. At each measurement occasion mean arterial (MAP) and central venous pressures (CVP), cardiac output (CO), temperatures, and blood gas analyses were obtained. Hemodynamically derived variables were calculated according to standard formulas.

Systemic vascular resistance (SVR) was calculated as follows:

$$
\mathrm{SVR}=\frac{\mathrm{MAP}-\mathrm{CVP}}{\mathrm{CO}} \times 80 \text { dyne } \times \sec \times \mathrm{cm}^{-5}
$$

where pressures were measured in millimeters of mercury and cardiac output in liters per minute.

Cardiac output was normalized to cardiac index (CI, $\mathrm{L} / \mathrm{min} \times \mathrm{m}^{2}$ ) by dividing with body surface area.

Oxygen contents $\left(\mathrm{CO}_{2}\right)$ of arterial and mixed venous blood were calculated as follows:

$$
\mathrm{Co}_{2}=\mathrm{Hb} \times 1.37 \times \mathrm{So}_{2}+0.0034 \times \mathrm{Po}_{2}(\mathrm{ml} / \mathrm{L})
$$

where hemoglobin $(\mathrm{Hb})$ is given in grams per deciliter, 1.37 is the volume of oxygen ( $\mathrm{ml}$ ) carried by $1 \mathrm{gm}$ of fully saturated hemoglobin, $\mathrm{So}_{2}$ is fractional oxygen saturation of hemoglobin, 0.0034 is the solubility coefficient of oxygen in plasma, and $\mathrm{Po}_{2}$ is the oxygen tension $(\mathrm{mm} \mathrm{Hg}$ ) in plasma.

The formula for oxygen delivery $\left(\mathrm{DO}_{2} \mathrm{I}\right)$ is as follows:

$$
\mathrm{Do}_{2} \mathrm{I}=\mathrm{CO}_{2} \times \mathrm{CI}\left(\mathrm{ml} / \mathrm{min} \times \mathrm{m}^{2}\right)
$$




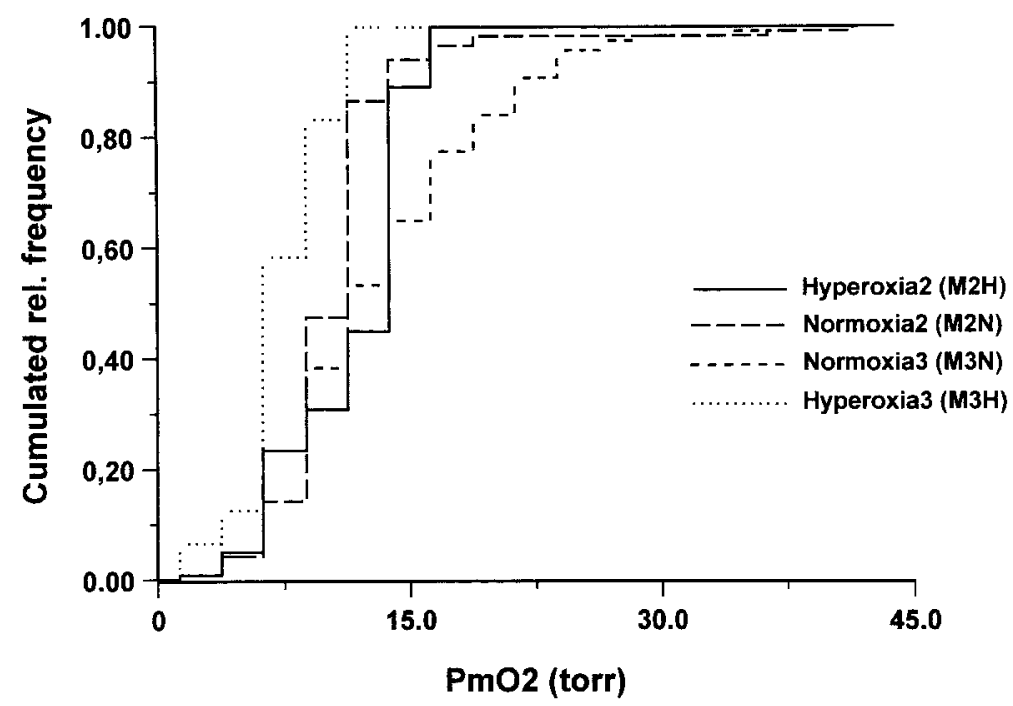

Fig. 2. $\mathrm{Pmo}_{2}$ during CPB for one patient (No. 6) under normoxemic and hyperoxemic conditions (Normoxia 2 and 3, M2N and M3N, and Hyperoxia 2 and 3, M2H and $M 3 H$ ). Values are presented as cumulated relative frequencies on the $y$-axis, with the 0.50 value corresponding to the median. Each of the four histograms is constructed from 120 separate $\mathrm{Pmo}_{2}$ values.

Oxygen consumption index $\left(\dot{\mathrm{V}}_{2} \mathrm{I}\right)$ was determined by this equation:

$$
\dot{\mathrm{VO}}_{2} \mathrm{I}=\mathrm{A}_{\mathrm{ADO}} \times \mathrm{CI}\left(\mathrm{ml} / \mathrm{min} \times \mathrm{m}^{2}\right)
$$

where $\mathrm{A}-\mathrm{vDO}_{2}$ is arteriovenous oxygen content difference.

$\mathrm{Pmo}_{2}$ measurements. An eight-channel oxygen microelectrode (L. Eschweiler and Co., Kiel, Germany) was used for measurements of skeletal muscle $\mathrm{PmO}_{2}$. ${ }^{9}$ The electrode consists of eight platinum wires. Each wire has a diameter of $15 \mu \mathrm{m}$ and is embedded in a glass cylinder. The electrode is covered with a cellophane inner membrane $(12 \mu \mathrm{m})$ containing potassium chloride in a concentration of $0.20 \mathrm{~mol} / \mathrm{L}$ and with an outer Teflon membrane $(12 \mu \mathrm{m})$. Sterilization and calibration of the electrode system was done according to the method of Lund and associates $^{8}$ and Ödman and Lund. ${ }^{10}$ At each measurement occasion the electrode was rotated 15 times at intervals of 10 seconds, giving a total of $120 \mathrm{Pmo}_{2}$ values. Thus sampling during a 3-minute period at each measurement generates a distribution of $\mathrm{PmO}_{2}$ values that can be used to create a histogram characterizing the state of tissue oxygenation at that occasion. The $\mathrm{Pmo}_{2}$ values were processed by an eight-bits resolution analog-to-digital converter and recorded and stored by a personal computer for subsequent calculations and data analyses. Muscle temperature was recorded. $\mathrm{PmO}_{2}$ values were corrected to actual muscle surface temperatures. The temperature effect on the electrode is $1.3 \% /{ }^{\circ} \mathrm{C}$. The electrode has a linear oxygen dependence in the temperature range of $20^{\circ}$ to $40^{\circ} \mathrm{C}$, which is taken into account in the calculation program.

After induction of anesthesia a small incision for mounting of the electrode on the surface of a muscle was made on the left leg, or the leg that was not used for harvesting of vein grafts in the case of CABG operations.
The fascia over the anterior tibial muscle was incised and removed in a small area, allowing the application of a Lucite methyl methacrylate ring. This ring served as an electrode holder, which was carefully placed on the exposed muscle surface. The body of the electrode and its cable were dressed in a sterile plastic sleeve, and the sterile electrode tip was mounted into the holder. Before the end of the study, samples for bacterial cultures were obtained from the application site.

Statistical analyses. $\mathrm{PmO}_{2}$ values from normoxemic and hyperoxemic conditions during each of the four stages of the operation were compared by means of two-way analysis of variance with Fisher's least significant difference comparison report using all valid $\mathrm{PmO}_{2}$ data for all patients at the respective occasion. For paired comparisons of hemodynamic and oxygen transport variables during hyperoxemic and normoxemic conditions, the Wilcoxon signed rank test was used with Bonferroni-adjusted significance levels. Results are presented as mean \pm standard deviation. Values of $p<0.05$ were considered to be statistically significant.

\section{Results}

Factors known to influence tissue perfusion, such as vasodilators, inotropic agents, or vasoconstrictors, were not used during CPB at all, but vasodilators were used in four patients before CPB and in two of those patients also after CPB. CPB duration was 99 \pm 14 minutes (mean \pm standard deviation) and aortic crossclamp time was $42 \pm 16$ minutes.

Temperatures of the nasopharynx, hemoglobin concentrations in blood, cardiac index, mixed venous oxygen saturations, and arterial oxygen ten- 


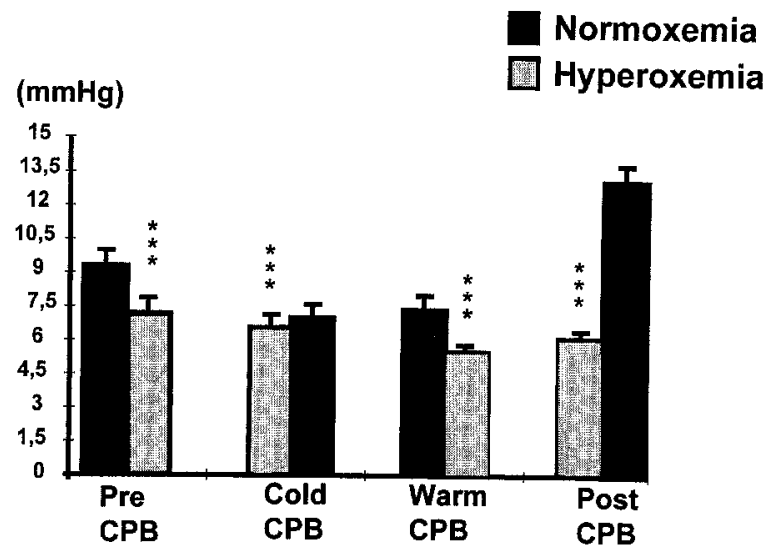

Fig. 3. Effects of normoxemia and hyperoxemia on mean $\mathrm{PmO}_{2}$ during four stages of surgery, during hypothermic as well as normothermic CPB, and before and after CPB. Means \pm standard deviations are given. Data were analyzed by analysis of variance. ${ }^{* * *} p<0.001$.

sions $\left(\mathrm{PaO}_{2}\right)$ are given in Table I for each measurement occasion. Nasopharyngeal temperature and hemoglobin concentrations showed no differences between normoxemic and hyperoxemic conditions at any of the four studied stages of the operation. Cardiac index was increased during rewarming but was otherwise similar at all stages. $\mathrm{PaO}_{2}$ values could be held within the intended ranges during measurements, were significantly different during normoxemic and hyperoxemic conditions $(p<0.001)$, and did not overlap. Venous oxygen saturations were higher during hyperoxemia, reaching statistical significance during hypothermic CPB and after CPB.

Tissue oxygenation. A common pattern during change from normoxemia to hyperoxemia was seen as an increase in distribution heterogeneity of $\mathrm{Pmo}_{2}$ values as well as an increasing number of low values. Distributions of $\mathrm{Pmo}_{2}$ values at the eight measurements from one randomly chosen patient are shown in Figs. 1 and 2. Also, mean $\mathrm{Pmo}_{2}$ values for the different measurement occasions were consistently and significantly lower during hyperoxemia than during normoxemia before and after CPB, as well as during hypothermic and normothermic CPB (Fig. 3).

Central hemodynamics and oxygenation. Global systemic oxygen delivery was slightly higher during hyperoxemia during both cold and warm CPB (Fig. 4). During normothermic CPB, measurements M3N and $\mathrm{M} 3 \mathrm{H}$, global systemic oxygen uptake was lower (Fig. 5), and systemic vascular resistance and mean

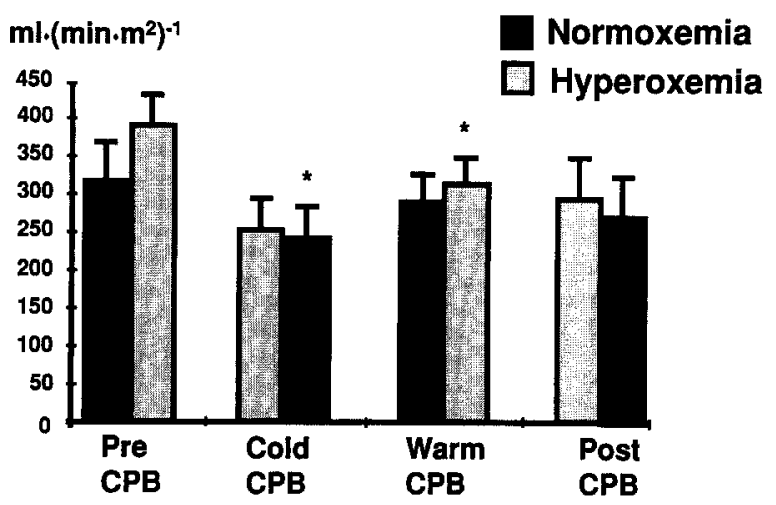

Fig. 4. Systemic oxygen delivery index during normoxemic versus hyperoxemic conditions during four different stages of surgery. Means \pm standard deviations are given. Paired comparisons were analyzed by means of the Wilcoxon signed rank test with Bonferroni-adjusted significance levels. ${ }^{*} p<0.05$.

arterial pressure $(p<0.05)$ were higher during hyperoxemia (Fig. 6). The values of mean arterial pressure followed the same pattern as that of systemic vascular resistance.

Clinical course. No positive bacterial cultures from the electrode application sites or clinical complications from that site were seen. Similarly no other clinical complications were noted.

\section{Discussion}

In this study hyperoxemia increased global oxygen delivery and oxygen saturation in mixed venous blood during CPB. This effect might be assumed to provide improved tissue oxygenation and safety. However, muscle oxygenation deteriorated during hyperoxemia. This paradoxic finding and other reported untoward effects of hyperoxemia during $\mathrm{CPB}^{4}$ call for further investigations about the effects and safety of hyperoxemia and suggest that hyperoxemia perhaps should be avoided.

In several investigations in which tissue oxygenation was studied, decreased oxygenation, sometimes even to hypoxic levels, together with signs of a maldistributed capillary flow has been found as a response to hyperoxemia. ${ }^{5-7}$ It is not known whether these capillary blood flow regulating mechanisms are maintained during hypotensive, hypothermic, or nonpulsatile flow conditions, such as CPB. In patients undergoing CABG operations, atherosclerosis present elsewhere in the vascular system may also interfere with these flow-regulating mechanisms. If 


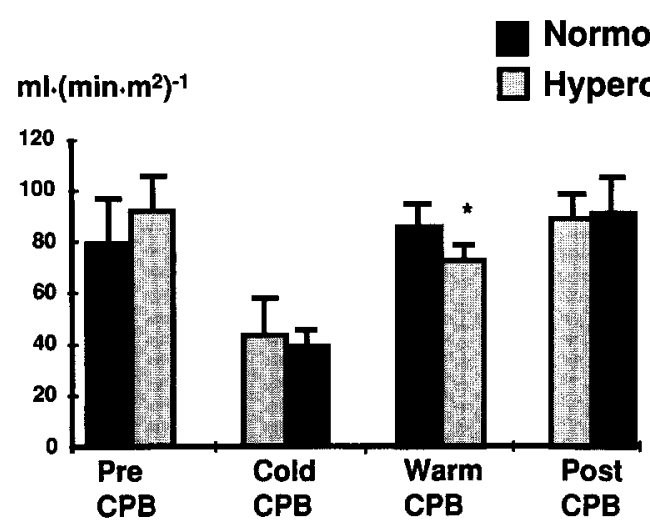

Fig. 5. Systemic oxygen uptake index during normoxemia and hyperoxemia before, during, and after CPB. Means \pm standard deviations are given. Paired comparisons were analyzed by means of the Wilcoxon signed rank test with Bonferroni-adjusted significance levels. ${ }^{*} p<0.05$.

the normal capillary flow response to hyperoxemia, that is, flow reduction, is not maintained, then hyperoxemia would probably provide improved tissue oxygenation. However, the results of this study show that the capillary flow-regulating mechanisms induced by hyperoxemia, described earlier in healthy volunteers ${ }^{5}$ and critically ill patients, ${ }^{6}$ remain present, irrespective of the decline in perfusion pressure, temperature, the presence of a nonpulsatile flow pattern, and probably concomitant atherosclerosis.

The organ surface microelectrode method used in this study ${ }^{11}$ measures close to the oxygen target, that is, at the capillary level near the cell. The multiplepoint setup supplies data of organ surface oxygen distributions, which are important because single oxygen measurements vary along and radially to the capillary. ${ }^{12}$ The local $\mathrm{PmO}_{2}$ values depend on the interaction between oxygen delivery and consumption. However, the $\mathrm{Pmo}_{2}$ values and especially the distributions of sampled $\mathrm{PmO}_{2}$ values are affected to a larger degree by capillary flow alterations rather than changes in local oxygen consumption. ${ }^{7}$ Low $\mathrm{PmO}_{2}$ values, as measured by this technique, are of physiologic importance because they may indicate hypoxic areas with concomitant local tissue acidosis. ${ }^{13}$ The shortcomings of the method are that organ surface measurements may not necessarily reflect deeper portions of the tissues. However, for skeletal muscle no anatomic differences exist between different locations within the muscle; thus it has been claimed that the results are indicative of
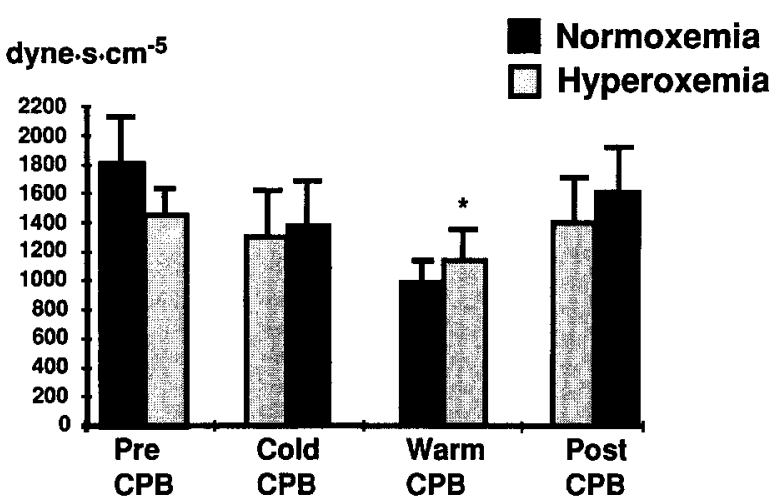

Fig. 6. Systemic vascular resistance during normoxemia and hyperoxemia before, during, and after CPB. Means \pm standard deviations are given. Paired comparisons were analyzed by means of the Wilcoxon signed rank test with Bonferroni-adjusted significance levels. ${ }^{*} p<0.05$.

the organ as a whole. ${ }^{14}$ One has to be cautious in extrapolating the results to other organs, however, especially those with structured capillary beds.

Oxygen has long been claimed to be one of the important factors regulating blood flow through its effect on the metabolism of parenchymal cells, which secondarily produce metabolites known to alter blood flow. ${ }^{15}$ The oxygen effects could also be mediated by the vessels themselves ${ }^{16}$ and by the endothelium. ${ }^{17,18}$ Most studies in this respect have investigated the effect of hypoxia/hypoxemia ${ }^{17,18}$ and few have thoroughly addressed the effects on capillary blood flow seen during hyperoxemia. However, previous studies, contrary to what was expected, have found decreasing tissue oxygen levels both in skeletal muscle ${ }^{5,6,19}$ and in the brain ${ }^{20}$ during exposure to hyperoxemia. Thorborg and coworkers, ${ }^{7}$ measuring capillary blood flow in skeletal muscle during hyperoxemia, found a decrease in capillary blood flow as the reason for the decreased tissue oxygen levels. It has been claimed that this flow change is mediated by increased capillary levels of serotonin, due either to a decrease in serotonin metabolism by the lung or endothelial cells ${ }^{21}$ or to a suggested increase in the release of serotonin by platelets. ${ }^{7}$ It has also been claimed that hyperoxemia inactivates the endothelium-derived relaxing factor (nitric oxide) and thereby causes vasoconstriction at the capillary level. ${ }^{22}$ Possibly, serotonin and the release of nitric oxide in hyperoxemia are also linked. ${ }^{23}$

Several of the factors that have been considered 
to be important for the hyperoxemically induced changes in capillary blood flow (e.g. inflammatory mediators, platelet function, platelet activation, serotonin release, and blood flow profile) may be affected by CPB. Platelets, granulocytes, coagulation, and inflammatory mediators are activated by the CPB circuit to produce a "whole body inflammatory response." 24,25 If vasoconstriction was the net effect, then this response might help to explain the low $\mathrm{PmO}_{2}$ values seen during $\mathrm{CPB}$ in this and a previous study. ${ }^{3}$ Pulsations are also known to stimulate vasodilation mediated by the endothelium, ${ }^{26}$ and the nonpulsatile flow during CPB might be attributable to the impaired capillary flow and oxygenation seen here and previously. ${ }^{3}$ However, $\mathrm{Pmo}_{2}$ values were low also before and after CPB. These low values might be attributable to the stable but low arterial blood pressures during anesthesia and are in agreement with the mechanism of flow and shear stress inducing vasodilation. ${ }^{27}$

Central hemodynamics were not influenced by the changes from normoxemia to hyperoxemia except for significantly higher systemic vascular resistance and mean arterial pressure and lower global oxygen uptake during hyperoxemic normothermic CPB, that is, late during the bypass period. Systemic effects of regional microvascular changes induced by hyperoxemia were not really expected. However, if the lowering of $\mathrm{PmO}_{2}$ and increased heterogeneity in the capillary perfusion seen during hyperoxemia were widespread in skeletal muscle or perhaps beyond that organ, the disturbance of capillary exchange of oxygen might be large enough to be detected systemically. This reasoning may also be valid for the observed effect on arterial pressure and vascular resistance. We believe that the hyperoxemic response works by constricting precapillary arterioles. A small but consistent increase of systemic vascular resistance index as a response to hyperoxemic periods both during and after CPB, although not statistically significant, has been reported previously. ${ }^{28}$ Systemic changes were not seen during the other stages of the operation; however, it may be argued that late during bypass the nonpulsatile flow and other profound changes discussed earlier, which are brought about by $\mathrm{CPB}$, might potentiate the hyperoxemic response of the microvasculature to significantly alter systemic parameters as well. Even though skeletal muscle capillary exchange of oxygen seems to be disturbed by hyperoxemia, there were no signs of concomitantly reduced mixed venous oxygen saturation at any occasion. This is, however, not to be expected because profound regional venous desaturation and even progressive regional acidemia may go undetected, while mixed venous saturation is normal. ${ }^{29}$

Thus our findings show that the mechanisms that regulate capillary flow and tissue oxygenation appear intact and that the untoward effects of hyperoxemia seen during other conditions also occur during normothermic and hypothermic CPB. The decrease in oxygen consumption after the rewarming period, during which increased values were to be expected, indicates an unfavorable capillary exchange of oxygen. A substantial body of evidence indicates that under both normal and disease states hyperoxemia disturbs capillary flow and can impair tissue oxygenation. Whether this is true also during $\mathrm{CPB}$ conditions, as seems to be the case in this study, has to be investigated further with respect to different organs and to its importance in relation to, for example, morbidity. If the untoward effects of hyperoxemia during CPB can be established further, this will call for continuous on-line monitoring of $\mathrm{PaO}_{2}$, not only as a safeguard to avoid hypoxia but also as a means of improving the quality in performing CPB and maintaining oxygen tensions within an optimal range.

We express our gratitude for valuable technical assistance to Lars-Åke Malmquist, laboratory engineer, and to Urban Gustafsson, research assistant.

REFERENCES

1. Alston RP, Singh M, McLaren AD. Systemic oxygen uptake during hypothermic cardiopulmonary bypass: effects of flow rate, flow character, and arterial $\mathrm{pH}$. J Thorac Cardiovasc Surg 1989;98:757-68.

2. Niinikoski J, Kuttila K. Adequacy of tissue oxygenation in cardiac surgery: regional measurements. Crit Care Med 1993;21(Suppl):S77-83.

3. Boekstegers P, Riessen R, Seyde W. Oxygen partial pressure distribution within skeletal muscle: Indicator of whole body oxygen delivery in patients? In: Piiper J, Goldstick TK, Meyer M, editors. Oxygen transport to tissue XII. New York: Plenum Press, 1990:507-14.

4. Belboul A, Al-khaja N, Ericson C, Löfgren C, Thornbolm C, Kurdi S, et al. The effect of hyperoxia during cardiopulmonary bypass on blood cell rheology and postoperative morbidity associated with cardiac surgery. J Extracorp Technol 1993;23:43-8.

5. Lund N, Jorfeldt L, Lewis DH. Skeletal muscle oxygen pressure fields in healthy human volunteers: a study of the normal state and the effects of different arterial oxygen pressures. Acta Anaesthesiol Scand 1980;24:272-8.

6. Lund N, Jorfeldt L, Lewis DH, Ödman S. Skeletal muscle oxygen pressure fields in artificially ventilated, critically ill patients. Acta Anaesthesiol Scand 1980;24:347-53. 
7. Thorborg P, Gustafsson U, Sjöberg F, Harrison DK, Lewis $\mathrm{DH}$. The effect of hyperoxemia and ritanserin on skeletal muscle microflow. J Appl Physiol 1990;68:1494-500.

8. Lund N, Cardell B, Törnell B-M, Ödman S. A technique for disinfection of the MDO oxygen electrode. Acta Anaesthesiol Scand 1980;24:265-71.

9. Kessler M, Höper J, Krumme BA. Monitoring of tissue perfusion and cellular function. Anesthesiology 1976;45:184-97.

10. Ödman S, Lund N. Data acquisition and information processing in MDO oxygen electrode measurement of tissue oxygen pressure. Acta Anaesthesiol Scand 1980;24:161-5.

11. Gutierrez G, Lund N, Acero AL, Marini C. Relationship of venous $\mathrm{PO}_{2}$ to muscle $\mathrm{PO}_{2}$ during hypoxemia. J Appl Physiol 1989;67:1093-9.

12. Krogh A. The number and distribution of capillaries in muscle with calculations of the oxygen pressure head necessary for supplying the tissue. J Physiol (Lond) 1919;52:409-15.

13. Sjöberg F, Gustafsson U, Lewis DH. Extracellular muscle surface $\mathrm{pO}_{2}$ and $\mathrm{pH}$ heterogeneity during hypovolemia and after reperfusion. Circ Shock 1991;34:319-28.

14. Thorborg PAJ. Skeletal muscle oxygenation and microflow: influence of oxygen, carbon dioxide and $5-\mathrm{HT}_{2}$ receptor antagonists. Linköping, Sweden: Linköping University Medical Dissertations, No. 288, 1989.

15. Hudlická O. Regulation of muscle blood flow. Clin Physiol 1985;5:201-29.

16. Duling BR. Changes in microvascular diameter and oxygen tension induced by carbon dioxide. Circ Res 1973;32:370-6.

17. Busse R, Pohl U, Kellner C, Klemm U. Endothelial cells are involved in the vasodilatory response to hypoxia. Pflugers Arch 1983;397:78-80.

18. Jackson WF. Arteriolar oxygen reactivity: Where is the sensor? Am J Physiol 1987;253:H1120-6.

19. Thorborg P, Malmquist L- $\AA$, Lund N. Surface oxygen pres- sure distributions in rabbit skeletal muscle: dependence on arterial $\mathrm{pO}_{2}$. Microcirc Endothelium Lymphatics 1988;4:16992.

20. Leniger-Follert E, Wrabetz W, Lübbers DW. Local tissue $\mathrm{pO}_{2}$ and microflow of the brain cortex under varying arterial oxygen pressure. In: Grote J, Reneau D, Theus G, editors. Oxygen transport to tissue. New York: Plenum Press, 1976: 316-7.

21. Block ER, Patel JM, Angelides KJ, Sheridan NP, Garg LC. Hyperoxia reduces plasma membrane fluidity: a mechanism for endothelial cell dysfunction. J Appl Physiol 1986;60:826-35.

22. Rubanyi GM, Vanhoutte PM. Superoxide anions and hyperoxia inactivate endothelium-derived relaxing factor. Am J Physiol 1986;250:H822-7.

23. Lüscher TF. Endothelium-derived nitric oxide: the endogenous nitrovasodilator in the human cardiovascular system. Eur Heart J 1991;12(Suppl E):2-11.

24. Edmunds LH Jr. Blood-surface interactions during cardiopulmonary bypass. J Card Surg 1993;8:404-10.

25. Downing SW, Edmunds LH Jr. Release of vasoactive substances during cardiopulmonary bypass. Ann Thorac Surg 1992;54:1236-43.

26. Pohl U, Busse R, Kuon E, Bassenge E. Pulsatile perfusion stimulates the release of endothelial autacoids. J Appl Cardiol 1986;1:215-35

27. Pohl U, Herlan K, Huang A, Bassenge E. EDRF-mediated shear-induced dilation opposes myogenic vasoconstriction in small rabbit arteries. Am J Physiol 1991;261:H2016-23.

28. Kuttila K. Response of tissue oxygenation to systemic hyperoxia after cardiac surgery. Crit Care Med 1990;18:369-72

29. McDaniel LB, Zwischenberger JB, Vertrees RA, Nutt L, Uchida T, Nguyen T, et al. Mixed venous oxygen saturation during cardiopulmonary bypass poorly predicts regional venous saturation. Anesth Analg 1995;80:466-72. 